\title{
Respiratory health in children, and indoor exposure to $(1,3)$ - $\beta$-D-glucan, EPS mould components and endotoxin
}

\author{
C. Tischer, U. Gehring, C-M. Chen, M. Kerkhof, G. Koppelman, S. Sausenthaler, \\ O. Herbarth, B. Schaaf, I. Lehmann, U. Krämer, D. Berdel, A. von Berg, C.P. Bauer, \\ S. Koletzko, H-E. Wichmann, B. Brunekreef and J. Heinrich
}

ABSTRACT: For a long time, exposure to mould and dampness-derived microbial components was considered a risk factor for the development of respiratory diseases and symptoms. Some recent studies suggested that early childhood exposure to mould components, such as (1,3)- $\beta$-Dglucan and extracellular polysaccharides (EPSs), may protect children from developing allergy. We investigated the association of exposure to $(1,3)-\beta$-D-glucan, EPS and endotoxin with asthma and allergies in 6-yr-old children.

This investigation was the follow-up to a nested case-control study among three European birth cohorts. Children from two ongoing birth cohort studies performed in Germany $(n=358)$ and one in the Netherlands $(n=338)$ were selected. Levels of $(1,3)-\beta$-D-glucan, EPS and endotoxin were measured in settled house dust sampled from children's mattresses and living-room floors when the children were, on average, 5 yrs of age. At the age of 6 yrs, health outcome information was available for 678 children.

In the two German subsets, domestic EPS and endotoxin exposure from children's mattresses were significantly negatively associated with physician-diagnosed asthma (OR per interquartile range increase 0.60 (95\% $\mathrm{Cl} 0.39-0.92)$ and 0.55 (95\% Cl $0.31-0.97)$, respectively). In addition, EPS exposure was inversely related to physician-diagnosed allergic rhinitis (OR $0.50,95 \% \mathrm{CI}$ 0.31-0.81). For the Dutch population, no associations were observed between exposure to microbial agents and respiratory health outcomes.

We found inverse associations between domestic exposure to EPS and endotoxin from children's mattresses, and doctor-diagnosed asthma and rhinitis in German, but not in Dutch, school children. The reasons for the differences between countries are not clear.

KEYWORDS: Allergy, asthma, childhood, endotoxin, rhinitis

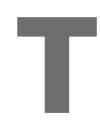
he effect of visible mould and mould components in indoor environments on asthma and allergic diseases in children has been widely discussed in recent years. Several studies have investigated the associations, but the results were not conclusive.

Some studies have shown that visible mould in homes increases the risk of physician-diagnosed asthma and wheezing in children [1-6]. A birth cohort study in the USA concluded that 1-yr-old children of asthmatic and allergic mothers who were exposed to high levels of Penicillium, a common genus of mould, were at significantly higher risk for wheeze and persistent cough [7].
Another US study showed that exposure to dustborne Aspergillus, Alternaria and Aureobasidium at 3 months of age was associated with the development of physician-diagnosed allergic rhinitis within the first 5 yrs of life [8].

Few studies measured biological components of mould, such as (1,3)- $\beta$-D-glucan and extracellular polysaccharides (EPSs), as surrogates for mould exposure $[3,9]$. $(1,3)-\beta$-D-glucans are nonallergenic, water-insoluble, structural cell wall components of most fungi. This biologically active polyglucose molecule may account for $\leqslant 60 \%$ of the dry weight of the fungal cell wall [10]. However, $(1,3)-\beta$-D-glucans are also part of the
AFFILIATIONS

A full list of the authors' affiliations can be found in the Acknowledgements section.

\section{CORRESPONDENCE}

J. Heinrich

Institute of Epidemiology Helmholtz Zentrum München German Research Centre for Environmental Health Ingolstaedter Landstrasse 1 D-85764 Neuherberg Germany

E-mail: joachim.heinrich@

helmholtz-muenchen.de

Received:

June 142010

Accepted after revision:

Aug 252010

First published online:

Sept 032010 
structure of plant materials, including pollen and cellulose, as well as soil bacteria; therefore, the level of mould exposure may be overestimated by using $(1,3)-\beta$-D-glucan as a surrogate. Fungal EPSs are stable carbohydrates secreted or shed during fungal growth and have antigenic specificity at the genus level. In contrast with the findings on visible mould and measured specific mould species, longitudinal studies showed that exposure to $(1,3)-\beta$-D-glucan and EPS was inversely associated with wheezing symptoms and parentally reported physiciandiagnosed asthma in children $[3,5,11]$. In addition, one casecontrol study reported that elevated levels of $(1,3)-\beta$-D-glucan and EPS exposure from mattress dust were associated with a lower prevalence of allergic sensitisation in 2-4-yr-old children [9]. However, the mechanism of these inverse effects is not yet understood. Different ways of assessing mould exposure could explain the conflicting results. HAAs et al. [12] reported that visible mould growth was significantly correlated with the concentration of fungal spores. As opposed this, a US cohort study did not observe a correlation between $(1,3)-\beta$-D-glucan exposure and visible mould $[3,5]$.

Early exposure to mould components compared with exposure later in life also showed a different impact on allergic health outcomes [13]. The immune response of newborns is dominated by T-helper (Th)2-cells and a shift to Th1-mediated immune response takes place during early childhood. It has been hypothesised that exposure to $(1,3)-\beta$-D-glucan and EPS may have a similar impact on the development of immune system of infants as early endotoxin exposure [3, 14, 15]. Endotoxins are cell wall components of the outer membrane of Gram-negative bacteria. They are ubiquitous and can be found in normal indoor environments as constituents of house dust. Exposure to endotoxin has been suggested to have strong immune-stimulatory properties [16, 17]. In support of the "hygiene hypothesis" [18, 19], previous studies showed that there is a lower prevalence of allergic sensitisation and physician-diagnosed asthma in children who were exposed to higher levels of endotoxin at home [9, 11, 20]. It was hypothesised that microbial products such as endotoxin could affect the development of children's immune systems early in life and play a crucial role in the development of tolerance to allergens ubiquitous in natural surroundings [21, 22].

We prospectively investigated the associations between exposure to mould components and endotoxin in settled house dust with respiratory and allergic health outcomes in 6-yr-old children using the data from two German birth cohorts and one Dutch birth cohort. This study is a continuation of the work that has been done within the AirAllerg study [9, 23]. Earlier AirAllerg investigations were based on health outcomes measured before exposure assessment. However, in the present analysis, health outcomes from the 6-yr follow-up were available after exposure assessment.

\section{MATERIALS AND METHODS}

\section{Study design and study population}

Three European birth cohort studies were included in this investigation: the German LISA (Lifestyle Related Factors on the Immune System and the Development of Allergies in Childhood) and GINI (German Infant Nutritional Intervention) studies, and the Dutch PIAMA (Prevention and Incidence of Asthma and Mite Allergy) study. LISA is a population-based birth cohort study. A total of 3,097 neonates were recruited between 1997 and 1999 in Munich, Leipzig, Wesel and Bad Honnef. The participants were not pre-selected based on family history of allergic diseases [24]. A total of 5,991 mothers and their newborns were recruited into the GINI study between September 1995 and June 1998 in Munich and Wesel. Infants with at least one allergic parent and/or sibling were allocated to the interventional study arm of the GINI study investigating the effect of different hydrolysed formulas for allergy prevention in the first year of life [25]. All children without a family history of allergic diseases and children whose parents did not give consent for the intervention were allocated to the noninterventional arm. Detailed descriptions of the LISA [24] and GINI [25] studies were published elsewhere. For the PIAMA study, a total of 4,146 pregnant females were recruited in 1996-1997 during their second trimester of pregnancy from a series of communities in the north, west and centre of the Netherlands. Nonallergic pregnant females were invited to participate in a "natural history" study arm. Pregnant females identified as allergic through the screening questionnaire were primarily allocated to an intervention arm with a random subset allocated to the natural history arm. The intervention involved the use of mite-impermeable mattress and pillow covers.

The three European birth cohorts described above were part of a collaborative nested case-control study (AirAllerg) within European birth cohorts (LISA, GINI and PIAMA) using the data on allergic sensitisation that have been collected at age 4 yrs in the Netherlands and at ages 2 and 3 yrs in Germany (fig. 1 and supplementary material 1). The target population size was $\sim 180$ sensitised children and 180 nonsensitised children as controls in each country. The controls were not matched by any criteria. Based on serum immunoglobulin (Ig)E determination, cases were defined as children who were sensitised to common aeroallergens. The number of children sensitised to aeroallergens was not reached in Germany and the Netherlands; the cases were supplemented with children sensitised to food. Allergen panels differed between the cohorts, but specific IgE to egg white, milk, house dust mites, cat, and tree and grass pollens were measured in all cohorts. Families should not have moved 6 months prior to the AirAllerg house-dust samplings. However, in Germany it was not possible to strictly follow this criterion; only $76 \%$ of the German participants fulfilled the criterion of not moving home. For the present investigation, 317 sensitised and 379 nonsensitised children were selected from the GINI, LISA and PIAMA birth cohort studies. At the age of $6 \mathrm{yrs}$, health endpoint data was available from 346 and 332 of the German and Dutch participants of the AirAllerg study, respectively.

\section{Questionnaire data}

In the German and Dutch populations, information on respiratory and allergic disorders, history of moving home, and visible mould in the child's home was collected at age 6 yrs, using self-administered questionnaires. An online supplement is provided to display the exact health outcome definitions within the 6-yr follow-up period of both subsets (see supplementary material 2). Information on parental educational level, family history of allergic diseases, smoking 

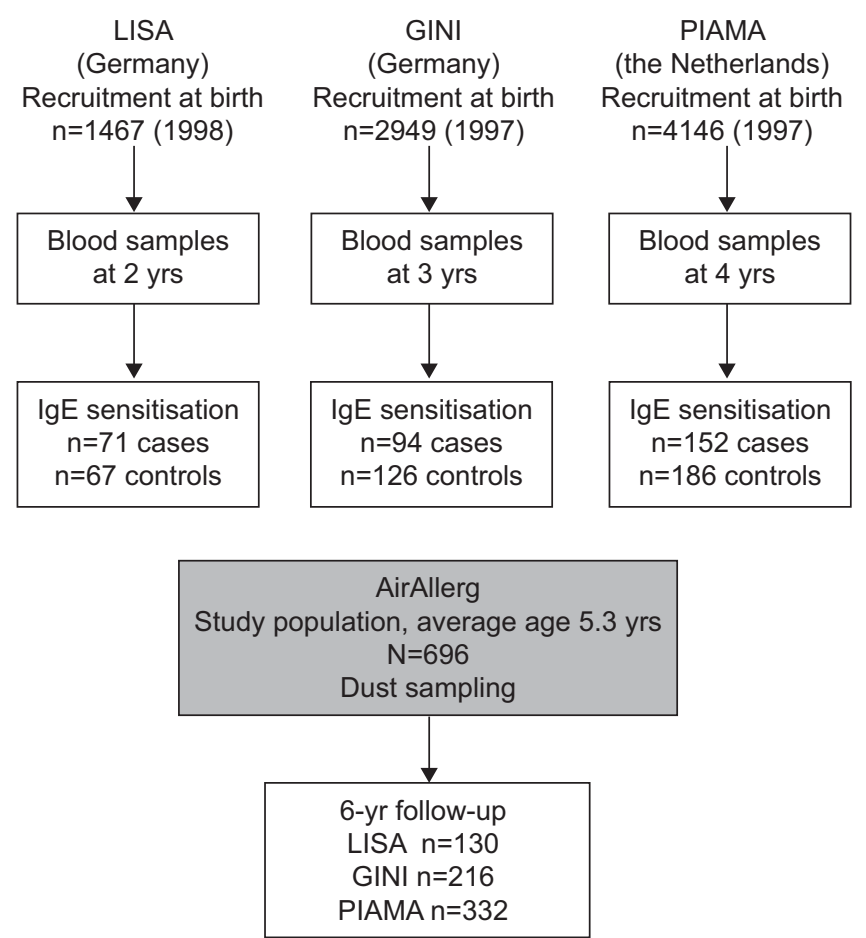

FIGURE 1. Study design and population. LISA: Lifestyle Related Factors on the Immune System and the Development of Allergies in Childhood; GINI: German Infant Nutritional Intervention; PIAMA: Prevention and Incidence of Asthma and Mite Allergy; Ig: immunoglobulin

during pregnancy and breast feeding were collected using selfadministered questionnaires during the first year of life.

\section{Dust collection}

Between January 2002 and May 2003, trained fieldworkers collected house-dust samples during home visits when the study children were, on average, 5 yrs (LISA and PIAMA) and 6 yrs (GINI) of age. A detailed description of the analysis and collection of the house-dust samples is provided elsewhere [23]. In brief, dust sampling was conducted using a common standard operation procedure of the AirAllerg study in the cool seasons. During the home visit, two settled house-dust samples from the child's mattress and the livingroom floor were collected by vacuuming. After dust sampling, the filters and the dust were stored at $-20^{\circ} \mathrm{C}$ until extraction.

\section{Dust extraction and analysis}

Dust, including filters, was extracted sequentially as described previously [14]. The first supernatant was used to measure endotoxin by a chromogenic kinetic Limulus amoebocyte lysate test [26]. The second supernatant was used to measure EPS of Aspergillus and Penicillium spp. by a sandwich enzyme immunoassay [27]. (1,3)- $\beta$-D-glucan was measured in the third supernatant with a $(1,3)-\beta$-D-glucan-specific inhibition enzyme immunoassay [28]. The detection limits of the assay were 0.05 endotoxin units $\cdot \mathrm{mL}^{-1}, 3.3 \mu \mathrm{g} \cdot \mathrm{mL}^{-1}$ and $0.9 \mathrm{EPS}$ units $\cdot \mathrm{mL}^{-1}$ for endotoxin, (1,3)- $\beta$-D-glucan and EPS of Aspergillus and Penicillium spp., respectively. Exposures were expressed as both per gram of sampled dust (concentration) and per square metre of sampling surface area (load). Samples of (1,3)- $\beta$-D-glucan and EPS below the limit of detection (LOD) were assigned a value of two-thirds of the respective LOD [11].

\section{Statistical analysis}

Distributions of the biocontaminant levels in house-dust samples were highly skewed and, therefore, were described using median (interquartile range (IQR)). Spearman's rank correlation coefficient was used to calculate the correlations. The skewed variables were log-transformed for further analysis. Generalised additive models using a local regression smoothing operation were fitted to assess the relationship of the associations between continuous indoor biological contaminants exposure and the logit of the binary health outcomes. Since most associations were linear, all exposure variables were used as continuous variables without transformation in further analyses.

Logistic regression models were used to determine associations between microbial exposure from children's mattresses and living-room floors, and allergic health outcomes. The confounders we adjusted for in logistic regression models were selected based on the literature. For the German subset, confounders included in all models were sex, parental allergy, parental education, current pet ownership, breastfeeding, case-control status in the AirAllerg study and season of dust sampling. Total amount of dust and endotoxin was additionally adjusted for current domestic exposure to environmental tobacco smoke (ETS). Visible mould exposure was adjusted for sex, parental allergy, parental education, outdoor activity in summer, breastfeeding, maternal smoking during pregnancy, study type and case or control status. Within the Dutch subset, confounders included in all models were sex, parental allergy, parental education, current domestic exposure to ETS, current pet ownership, breastfeeding, AirAllerg case-control status and season of dust sampling. Since the AirAllerg study is not a population-based sample and selected based on sensitisation status, we adjusted for case-control status in order to avoid bias. Being a case or a control within the study population not only affected the health outcomes in terms of allergic diseases and symptoms, but also the exposure and is, therefore, a confounder that we took into account for the current investigation.

The results are presented as OR $(95 \% \mathrm{CI})$ for an IQR increase in microbial exposure. We focused on exposure from children's mattresses due to a considerable amount of nondetectable values from living-room floor dust samples. The analyses were performed using SAS version 9.1 (SAS Institute Inc., Cary, NC, USA).

\section{RESULTS \\ Study population}

A total of 346 German and 332 Dutch children with information on domestic microbial exposure, and respiratory and allergic health outcomes were included in the analysis. Baseline characteristics and health outcomes assessed at the age of $6 \mathrm{yrs}$ are presented in table 1. There were some significant differences between the German and Dutch subsets. A higher percentage of the Dutch children were exposed to visible mould and were reported to have a pet at home compared with the German cohort. A considerable number of 
TABLE 1 Description of the German and Dutch AirAllerg study population at age 6 yrs

\begin{tabular}{|c|c|c|c|}
\hline Subjects $n$ & 358 & 332 & \\
\hline LISA & $138(39)$ & & \\
\hline GINI & $220(61)$ & & \\
\hline Males & 204/358 (57) & $186 / 332(56)$ & 0.859 \\
\hline High & 198/358 (55) & $193 / 332(56)$ & 0.502 \\
\hline Medium & $106 / 358(30)$ & 110/332 (33) & 0.360 \\
\hline Low & $54 / 358(15)$ & 29/332 (9) & 0.014 \\
\hline Visible mould in any room at 6 yrs of age & $56 / 323(17)$ & $108 / 329(33)$ & $<0.001$ \\
\hline Dwelling considered damp at 6 yrs of age & 10/339 (3) & NA & NA \\
\hline 3rd year & $68 / 319(19)$ & $133 / 326(41)$ & $<0.001$ \\
\hline 4th year & 257/324 (72) & 244/324 (75) & 0.260 \\
\hline Breastfeeding $^{+}$ & 179/333 (54) & $201 / 328(61)$ & 0.060 \\
\hline Smoking in child's home at 6 yrs of age & $72 / 344(21)$ & $89 / 331(27)$ & 0.084 \\
\hline Maternal smoking during pregnancy & $50 / 357(14)$ & 45/328 (14) & 0.985 \\
\hline Moving home $e^{5}$ at 6 yrs of age & $39 / 346(11)$ & $13 / 330(4)$ & $<0.001$ \\
\hline Physician-diagnosed asthmaf & $17 / 343(5)$ & 27/328 (8) & 0.119 \\
\hline Physician-diagnosed allergic rhinitis ${ }^{f, \# \#}$ & $47 / 342(14)$ & $24 / 327(7)$ & 0.010 \\
\hline \multicolumn{4}{|l|}{ Allergic respiratory symptoms ${ }^{f}$} \\
\hline Rhinoconjunctivitis & $48 / 343(14)$ & $28 / 327(7)$ & 0.036 \\
\hline Wheezing & $43 / 341(13)$ & 48/331 (15) & 0.546 \\
\hline Dry cough & $56 / 343(16)$ & $80 / 330(24)$ & 0.014 \\
\hline
\end{tabular}

Data are presented as $n, n(\%)$ or $n / N(\%)$, unless otherwise stated. Bold indicates statistically significant p-values. LISA: Lifestyle Related Factors on the Immune System and the Development of Allergies in Childhood; GINI: German Infant Nutritional Intervention; PIAMA: Prevention and Incidence of Asthma and Mite Allergy; NA: not available. " : defined as asthma and/or hay fever and/or eczema (at least one parent) for LISA and GINI and as asthma and/or allergy to house dust (mite) or pets, and/or hay fever in at least one parent for PIAMA; ": categorised according to the German educational system as less than, equal to and more than grade 10 for low, medium and high, respectively, for LISA and GINI and as the highest attained educational level of mother and father, where low is primary school, lower vocational or lower secondary education, medium is intermediate vocational education or intermediate/ higher secondary education, and high is higher vocational education and university for PIAMA;

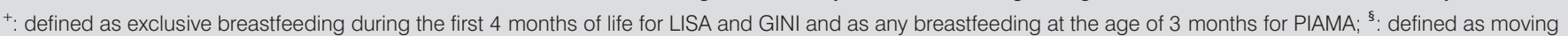

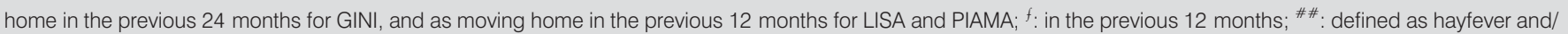
or allergic rhinitis (all seasons) for LISA and GINI, and as hayfever ever for PIAMA; " $"$ : defined as nocturnal dry cough for PIAMA; ${ }^{+}$: autumn defined as OctoberNovember, winter as December-February and spring as March-April.

the Dutch subjects, but only a small number of the German children, had visited day-care within the first year of life. The prevalence of physician-diagnosed respiratory infections in the previous 12 months at the age of 6 yrs was five times higher among the German compared with the Dutch population. The German children often reported more physician-diagnosed allergic rhinitis and rhinoconjunctivitis, whereas the Dutch children showed a higher prevalence of nocturnal dry cough. The season of dust sampling differed considerably between Germany and the Netherlands.

\section{Amount of dust sampled, and (1,3)- $\beta$-D-glucan, EPS and endotoxin levels}

The number of samples below the LOD, the median (IQR) of total amount of dust, mould components and endotoxin measured from domestic dust samples are presented in table 2. Wilcoxon tests showed significant differences in biocontaminant levels measured between the cohorts. Endotoxin and $(1,3)$ - $\beta$-D-glucan loads, and $(1,3)-\beta$-D-glucan concentrations from children's mattresses in Germany were significantly than the Dutch sample. There were weak correlations between the 
TABLE 2 Biocontaminant levels measured from children's mattress and living-room floors

\begin{tabular}{|c|c|c|c|}
\hline Subjects n & $358^{\#}$ & 332 & \\
\hline Amount of dust $\mathrm{mg} \cdot \mathrm{m}^{-2}$ & 0/257 (139-471) & 0/247 (148-366) & 0.322 \\
\hline Endotoxin $\mathrm{EU} \cdot \mathrm{m}^{-2}$ & 2/3053 (1521-6015) & 0/2356 (1461-4208) & 0.003 \\
\hline$(1,3)-\beta$-D-glucan $\mu \mathrm{g} \cdot \mathrm{m}^{-2}$ & 0/421 (238-865) & 0/380 (199-625) & 0.002 \\
\hline Endotoxin $\mathrm{EU} \cdot \mathrm{g}^{-1}$ & 2/12222 (7379-21337) & 0/10608 (6550-17366) & 0.021 \\
\hline$(1,3)-\beta$-D-glucan $\mu \mathrm{g} \cdot \mathrm{g}^{-1}$ & 0/1859 (1277-2396) & 0/1662 (1135-2205) & 0.002 \\
\hline EPS EPSU $\cdot g^{-1}$ & 6/40792 (24235-65371) & 5/34696 (20364-58156) & 0.021 \\
\hline \multicolumn{4}{|l|}{ Living-room floor dust load } \\
\hline Amount of dust $\mathrm{mg} \cdot \mathrm{m}^{-2}$ & 0/200 (52-523) & 22/104 (31-564) & 0.040 \\
\hline Endotoxin $\mathrm{EU} \cdot \mathrm{m}^{-2}$ & 14/3749 (1034-10212) & 23/2299 (441-14224) & 0.126 \\
\hline Endotoxin $\mathrm{EU} \cdot \mathrm{g}^{-1}$ & $14 / 19400(10104-32678)$ & 23/18196 (9522-32106) & 0.451 \\
\hline$(1,3)-\beta$-D-glucan $\mu \mathrm{g} \cdot \mathrm{g}^{-1}$ & 0/2229 (1703-3114) & 7/2137 (1519-2994) & 0.130 \\
\hline EPS EPSU $\cdot g^{-1}$ & 28/39344 (18290-76367) & 70/20330 (3896-61555) & $<0.001$ \\
\hline
\end{tabular}

Data are presented as $n /$ median (interquartile range), where $n$ is the number of values below the limit of detection, unless otherwise stated. Bold indicates statistically significant p-values. LISA: Lifestyle Related Factors on the Immune System and the Development of Allergies in Childhood; GINI: German Infant Nutritional Intervention; PIAMA Prevention and Incidence of Asthma and Mite Allergy; EU: endotoxin units; EPS: extracellular polysaccharide; EPSU: EPS units. ${ }^{*}:$ two subjects more than in [9] ( $n=356$ ).

biocontaminant levels from children's mattresses and livingroom floors both for surface load and per gram of dust (Spearman's correlation coefficient: GINI and LISA $<0.25$, PIAMA <0.13). The correlations between (1,3)- $\beta$-D-glucan, EPS and endotoxin from mattress dust samples were weak when these were expressed as units per gram of collected dust; however, the correlations were stronger when they were defined as surface loads (table 3).

\section{Associations between mould components and endotoxin, and respiratory diseases and symptoms}

Adjusted logistic regression models showed inconsistent results in the German and Dutch subsets. In the German population, EPS and endotoxin exposure from children's mattresses was significantly negatively associated with physiciandiagnosed asthma (OR per IQR 0.60 (95\% CI 0.39-0.92) and OR 0.55 (95\% CI 0.31-0.97), respectively). EPS exposure was also

TABLE 3 Correlation between the measured microbial components

\begin{tabular}{|c|c|c|c|c|c|c|c|c|}
\hline & \multicolumn{4}{|c|}{ LISA and GINI } & \multicolumn{4}{|c|}{ PIAMA } \\
\hline & Dust & $(1,3)-\beta$-D-glucan & EPS & Endotoxin & Dust & $(1,3)-\beta$-D-glucan & EPS & Endotoxin \\
\hline \multicolumn{9}{|c|}{ Children's mattresses } \\
\hline Dust & 1.00 & & & & 1.00 & & & \\
\hline (1,3)- $\beta$-D-glucan & 0.86 & 1.00 & 0.04 & 0.24 & 0.78 & 1.00 & 0.13 & 0.15 \\
\hline EPS & 0.76 & 0.67 & 1.00 & 0.22 & 0.70 & 0.63 & 1.00 & 0.07 \\
\hline Endotoxin & 0.63 & 0.66 & 0.60 & 1.00 & 0.59 & 0.54 & 0.51 & 1.00 \\
\hline \multicolumn{9}{|l|}{ Living-room floor } \\
\hline Dust & 1.00 & & & & 1.00 & & & \\
\hline$(1,3)$ - $\beta$-D-glucan & 0.94 & 1.00 & 0.21 & 0.26 & 0.95 & 1.00 & 0.36 & 0.42 \\
\hline EPS & 0.87 & 0.89 & 1.00 & 0.24 & 0.90 & 0.89 & 1.00 & 0.49 \\
\hline Endotoxin & 0.87 & 0.88 & 0.82 & 1.00 & 0.93 & 0.93 & 0.87 & 1.00 \\
\hline
\end{tabular}

Data are presented as Spearman's $\rho$. Amount of dust sampled is per square metre of surface area. Endotoxin, (1,3)- $\beta$-D-glucan and extracellular polysaccharide (EPS) levels are per gram of dust (concentration; bold only) or per square metre of surface area (load; bold and italic). LISA: Lifestyle Related Factors on the Immune System and the Development of Allergies in Childhood; GINI: German Infant Nutritional Intervention; PIAMA: Prevention and Incidence of Asthma and Mite Allergy. 
inversely related to physician-diagnosed allergic rhinitis (OR 0.67, 95\% CI 0.49-0.92) (table 4). Further stratification for parental allergy showed similar effects in children with allergic parents; however, the confidence intervals are wide. No effect on respiratory symptoms was observed. For the Dutch population, we could not find any effect of exposure to biocontaminants on any health outcomes assessed (table 5). The associations between exposure from living-room floor dust and assessed health outcomes were similar to exposure from children's mattresses, but were not significant (data not shown); this may be due to a higher number of nondetectable values for living-room floor dust samples compared with mattress dust samples.

In both samples, (1,3)- $\beta$-D-glucan, EPS, endotoxin and total amount of dust were highly correlated. Mutual adjustment for microbial exposure did not change the observed effects.

\section{Associations between visible mould exposure and endotoxin and respiratory diseases and symptoms}

We further investigated the effect of visible mould exposure on allergic respiratory disorders. A total number of 56 (17\%) homes in Germany and 108 (33\%) homes in the Netherlands were reported as having visible mould. We could not observe any association between visible mould exposure and any health outcome assessed within the German and Dutch sample (table 6).

\section{DISCUSSION}

Although we investigated birth cohort studies with a longitudinal design, exposure and health outcome assessment were only measured at one time point between the ages of 5 and 6 yrs. However, in contrast with earlier AirAllerg investigations, we were now able to measure health outcomes after exposure assessment. A further reason for the present study design is that before and after the age of 6 yrs, the German and Dutch birth cohorts had different time points of follow-up (i.e. PIAMA was investigated every year while the intervals for the GINI and LISA were less regular). To have at least one common, comparative time-point with a standardised exposure and health outcome measurement, we determined the 6-yr follow-up as a common reference.

Our results showed a mixed picture of the relationship between exposure to biocontaminant levels at home and the risk of respiratory diseases and symptoms in the three birth cohorts. In the German population, exposures to total amount of dust, (1,3)- $\beta$-D-glucan, EPS and endotoxin from children's mattresses were associated with a lower risk of respiratory diseases. In contrast, in the Dutch sample, there was no association between domestic microbial exposures and any health outcomes assessed. To our knowledge, this investigation is the first study which reports the effects of exposure to domestic mould components on allergic and respiratory health in school-age children.

Within the German sample, exposure to higher levels of $(1,3)$ - $\beta$-D-glucan and EPS at home from children's mattresses was inversely related to the risk of respiratory diseases. It was considered that exposure to mould components, such as $(1,3)$ - $\beta$-D-glucan and EPS, may have immune stimulatory properties $[9,11,14]$. A US birth cohort study observed that exposure to high levels of $(1,3)-\beta$-D-glucan from settled house

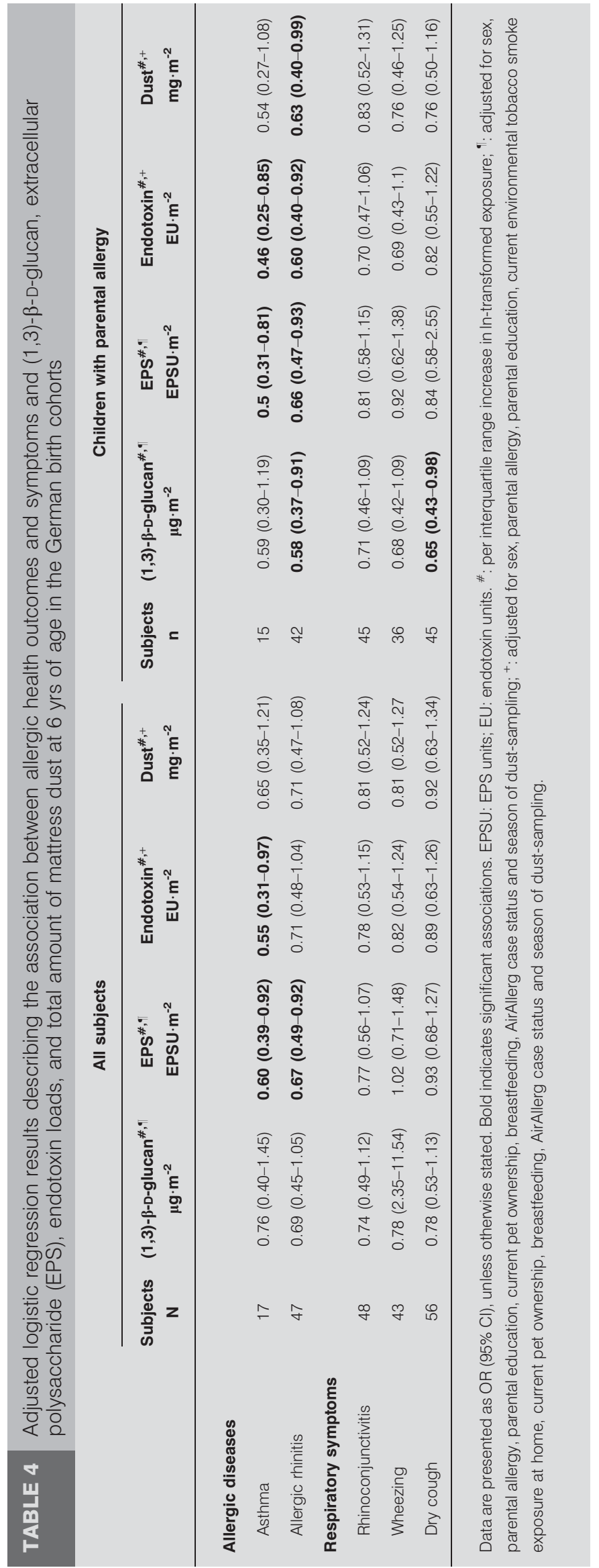




\begin{tabular}{|c|c|c|c|}
\hline \multirow[t]{3}{*}{ TABLE 6} & \multicolumn{3}{|c|}{$\begin{array}{l}\text { Adjusted logistic regression results describing } \\
\text { the association between allergic health } \\
\text { outcomes and symptoms and visible mould in } \\
\text { any room at home at } 6 \text { yrs of age }\end{array}$} \\
\hline & & \multicolumn{2}{|c|}{ Visible mould } \\
\hline & & Germany ${ }^{\#}$ & The Netherlands ${ }^{\pi}$ \\
\hline Subjects n & & 56 & 108 \\
\hline \multicolumn{4}{|c|}{ Allergic diseases } \\
\hline Asthma & & $1.03(0.26-4.16)$ & $1.14(0.48-2.70)$ \\
\hline Allergic rhin & & $1.77(0.79-3.99)$ & $1.60(0.62-4.14)$ \\
\hline \multicolumn{4}{|c|}{ Respiratory symptoms } \\
\hline Rhinoconju & ctivitis & $1.36(0.56-3.26)$ & $0.58(0.22-1.53)$ \\
\hline Wheezing & & $1.29(0.52-3.21)$ & $1.28(0.65-2.49)$ \\
\hline Dry Cough & & $1.27(0.59-2.76)$ & $1.24(0.71-2.15)$ \\
\hline
\end{tabular}

Data are presented as $\mathrm{OR}(95 \% \mathrm{Cl})$. \#: adjusted for sex, parental allergy, parental education level, outdoor activity (in hours), breastfeeding, maternal smoking during pregnancy and AirAllerg case-status; ' : adjusted for sex, parental allergy, parental education, current environmental tobacco smoke exposure at home, current pet ownership, breastfeeding, study arm and AirAllerg case-status; ${ }^{+}$: defined as physician-diagnosed allergic rhinitis in Germany and as hayfever in the Netherlands.

dust in the first year of life was associated with a persistent decreased risk for recurrent wheezing among genetically predisposed children up to the age of $3 \mathrm{yrs}[3,5]$. DouwES et al. [11] observed a statistically significant protective effect of Penicillium and Aspergillus EPS exposure from living-room floor dust at the age of 3 months on persistent wheeze in the first 4 yrs of life in the whole Dutch PIAMA study population. In the previous AirAllerg case-control investigation, higher amounts of mattress dust were reported to decrease the risk of allergic sensitisation to inhalant allergens in 2-4-yr-old children [9]. Compared with the German sample, we could not observe any effect of exposure to mould components on the risk of respiratory diseases and symptoms within the Dutch sample. We also investigated the exposure of visible mould at home and the risk of respiratory disorders. There are a number of studies considering visible mould as a risk factor for respiratory diseases and symptoms among children $[1,2$, 4-6]. We found no association between visible mould and respiratory disorders within the German and Dutch populations. However, there was no evidence that the mould components are associated with visible mould. This is in agreement with a recent cohort study in the USA, which did not observe a correlation between (1,3)- $\beta$-D-glucan and EPS mould components and visible mould [3,5]. Furthermore, it is known that $(1,3)-\beta$-D-glucan also derives from many other sources than mould, such as pollen or plants, which may explain the differences. Since the indoor environment consists of a variety of indoor and outdoor sources, not only the measured ones, a clear assignment to the observed health effects is difficult.

In addition, our investigation showed that exposure to higher levels of endotoxin at home from children's mattresses was inversely related to the risk of asthma within the German 
population. In support of the "hygiene hypothesis", which postulates an inverse effect of household size and siblings on the risk of hayfever $[18,19]$, there was a considerable number of epidemiological studies in the past investigating the effect of living on a farm and the risk of allergic disorders (for a review, see [29]). The farm environment contains large amounts of microbial products, including endotoxin [30]. Endotoxin has been suggested to have strong immune-stimulatory properties. It may therefore be capable of enhancing the Th1-dominated immune response and suppress the Th2-dominated allergic response in newborns and infants [16, 17]. Being born and growing up on a farm was protective against the risk of developing hayfever and allergic sensitisation early in life and some recent studies suggested that these protective effects are persistent until adulthood [29, 31]. A protective effect on respiratory and atopic disorders in children was also observed for domestic endotoxin exposure in nonfarming environments. Children who were exposed to a high level of endotoxin at home showed a lower prevalence of physician-diagnosed asthma and allergic sensitisation in the first years of life [9, 11, $20,32]$. A recent investigation of a US birth cohort showed that exposure to the Gram-negative bacterial biomarker endotoxin was inversely associated with asthma and allergic sensitisation at school age [32]. The inverse association of exposure to high levels of endotoxin at home and the risk of asthma could be also observed in our German sample.

The major strengths of our study are the comparison of three European birth cohort studies with a similar study design and a standardised exposure measurement from two different countries. We observed that endotoxin and $(1,3)-\beta$-D-glucan loads, and (1,3)- $\beta$-D-glucan concentrations from children's mattresses in Germany were significantly higher compared with the Dutch sample. Furthermore, the percentage of children exposed to visible mould was higher among the Dutch sample, which could indicate the presence of an increased exposure to microbial components other than those measured here. Moreover, the population density outside the domestic area may also have different impact on the children's exposure to microbial contaminants. In our study, the German children were all recruited from within and around Munich, whereas the Dutch children were recruited from several communities all over the Netherlands. In a recent PIAMA investigation, CAUDRI et al. [33] presented the number of addresses per square kilometre as a proxy for the degree of urbanisation. As for our study population, $87 \%$ of the Dutch children and $94 \%$ of the German children lived in an area with more than 1,500 addresses in a circular buffer with a 1,000-m radius. We investigated whether the degree of population density was associated with an increase in microbial exposures. However, there was no clear association between biocontaminants measured from children's mattresses and living-room floor exposure, and the number of addresses in a circular buffer with a 1,000-m radius.

A limitation of the present study is that it had only a single dust sampling over a period of 6 yrs. Dust samples of a single time-point cannot represent the overall exposure, as the microbial components in house dust samples may change over time. A previous AirAllerg investigation showed that the within-home variance of endotoxin, (1,3)- $\beta$-D-glucan and EPS measurements was small compared with the between-home variance [34]. However, some investigations looked at variations over time and performed repeatability analyses within and between homes. HEINRICH et al. [35] concluded that a single dust sampling and analysis of endotoxin is representative of the exposure to these components for at least a period $\leqslant 1 \mathrm{yr}$. To take into account the importance of early-life exposure to biocontaminants on the developing immune system, we restricted the analysis to those children who never changed residential location since birth. We observed that although associations between exposure to microbial components and physician-diagnosed asthma, as well as allergic symptoms, were getting smaller within the German subset, exposure to domestic $(1,3)-\beta$-D-glucan, EPS and total amount of dust from children's mattresses was getting more pronounced for the risk of physician-diagnosed allergic rhinitis. Within the Dutch subset, we observed a significant inverse effect of exposure to domestic endotoxin from children's mattresses with the risk of physician-diagnosed hayfever. The results indicate that a single biocontaminant measurement provides a reasonable proxy of the levels that were present since early life, at least among those children who never changed residential location.

Furthermore, the prevalence of early day-care attendance as another source of exposure to microbial contaminants differed considerably between the German and the Dutch samples: $2 \%$ of the German children but $25 \%$ of the Dutch children had visited a large scale day-care institution within the first year of life. This difference is persistent up to the age of 4 yrs. A number of studies observed a higher infection rate among children with early day-care [36, 37], which was confirmed for the Dutch PIAMA children in a recent investigation. Early daycare and the presence of older siblings was associated with more airway symptoms until the age of 4 yrs [33]. At the age of 6 yrs, infection rates among the Dutch PIAMA children were considerably lower than for the German children. Therefore, the impact of indoor exposure at home at the age of 6 yrs on the developing immune system may be attenuated within the Dutch subset due to a higher amount of multiple exposures early in life. However, when restricting analysis to those children who did not attend a large-scale day-care facility during the first year of life, we could not observe any effect on respiratory health at school age.

Based on our study design, we cannot exclude the possibility of reverse causation. A considerable proportion of the German and Dutch parents (82\% and $78 \%$, respectively) had allergic diseases, and they may therefore more frequently remove mould or dust, especially when having children diagnosed with allergic disorders. However, there is little literature on cleaning habits in relation to the levels of mould components or endotoxin in settled house dust and no indication of a greater variability in dust amount [38-40]. In our study, levels of $(1,3)-\beta$-D-glucan, EPS and the total amount of dust from children's mattresses were not different between allergic and nonallergic parents, except that there was a significantly lower endotoxin load from homes of genetically predisposed children in Germany. Further, seasonal variation as a possible factor of influence on the actual microbial exposure could also be excluded. House-dust sampling was performed during the cold season (October-April) only and the differences in the endotoxin loads between the sampling months were not 
statistically significant for the German subset. In PIAMA, the amount of dust per square metre and the (1,3)- $\beta$-D-glucan levels per gram of dust, both from the children's matresses, were significantly associated with the month of dust collection. However, given the large overall variability in exposure levels between the homes, the seasonal variation can be neglected as a reason for the biased results.

Considering all of the potential reasons for the inconsistent findings in the German and Dutch population discussed here, we cannot provide a sufficient explanation for the observed differences.

\section{Conclusion}

Domestic microbial exposure showed different effects on allergic disorders among the German and the Dutch samples. We found inverse associations between domestic exposure to EPS and endotoxin from children's mattresses, and doctordiagnosed asthma and rhinitis in German but not in Dutch school children. The reason for the differences between countries is not clear and requires further study.

\section{STATEMENT OF INTEREST}

None declared.

\section{ACKNOWLEDGEMENTS}

The authors' affiliations are as follows: C. Tischer, C-M. Chen, S. Sausenthaler and J. Heinrich, Institute of Epidemiology, Helmholtz Zentrum München, German Research Centre for Environmental Health, Neuherberg, Germany; U. Gehring, Institute for Risk Assessment Sciences, University of Utrecht, Utrecht, the Netherlands; M. Kerkhof, Dept of Epidemiology, University Medical Center Groningen, University of Groningen, Groningen, the Netherlands; G. Koppelman, Dept of Paediatric, Pulmonology and Paediatric Allergology, Beatrix Children's Hospital, University Medical Center Groningen, Groningen; O. Herbarth, Faculty of Medicine, Environmental Medicine and Hygiene, University Leipzig and Human Exposure Research and Epidemiology, Helmholtz Centre for Environmental Research-UFZ, Leipzig, Germany; B. Schaaf, Praxis für Kinder- und Jugendmedizin, Bad Honnef, Germany; I. Lehmann, Dept of Environmental Immunology, Helmholtz Centre for Environmental ResearchUFZ, Leipzig; U. Krämer, Institute für Umweltmedizinische Forschung (IUF), Heinrich-Heine-University, Düsseldorf, Germany; D. Berdel and A. von Berg, Dept of Paediatrics, Marien-Hospital Wesel, Wesel, Germany; C.P. Bauer, Dept of Pediatrics, Technical University of Munich, Munich, Germany; S. Koletzko, Dr. von Hauner Children's Hospital, Ludwig-Maximilians University of Munich, Munich; H-E. Wichmann, Institute of Epidemiology, Helmholtz Zentrum München, German Research Centre for Environmental Health, Neuherberg and Institute of Medical Data Management, Biometrics and Epidemiology, Ludwig-Maximilians University of Munich, Munich; B. Brunekreef, Institute for Risk Assessment Sciences, University of Utrecht, Utrecht and University of Groningen, University Medical Center, Julius Center for Health Sciences and Primary Care, Utrecht.

The authors wish to thank all families for their participation in the AirAllerg study. Furthermore, the authors are indebted to all of the scientists and technical staff involved in the planning and conduction of the AirAllerg study (Utrecht University, Institute for Risk Assessment, Utrecht, and the National Institute of Public Health and the Environment (RIVM), Bilthoven, the Netherlands; German Research Center for Environmental Health $(\mathrm{GmbH})$, Institute of Epidemiology, Neuherberg, Germany; GINI; LISA; German Research Center for Environmental Health $(\mathrm{GmbH})$, Institute of Epidemiology, Neuherberg; the Ludwig-Maximilians University Munich, Institute of
Medical Data Management, Biometrics and Epidemiology; and the Technical University of Munich, Dept of Paediatrics, Munich, Germany) and PIAMA birth cohort studies (Utrecht University, Institute for Risk Assessment Sciences, Utrecht; the Beatrix Children's Hospital and Dept of Epidemiology, Groningen University, Groningen; Sophia Children's Hospital, Rotterdam University, Rotterdam; RIVM, Bilthoven, and the Central Laboratory of Red Cross Blood Transfusion Service, Amsterdam, the Netherlands).

\section{REFERENCES}

1 Pekkanen J, Hyvarinen A, Haverinen-Shaughnessy U, et al. Moisture damage and childhood asthma: a population-based incident case-control study. Eur Respir J 2007; 29: 509-515.

2 Antova T, Pattenden S, Brunekreef B, et al. Exposure to indoor mould and children's respiratory health in the PATY study. J Epidemiol Community Health 2008; 62: 708-714.

3 Iossifova YY, Reponen T, Bernstein DI, et al. House dust (1-3)- $\beta$-Dglucan and wheezing in infants. Allergy 2007; 62: 504-513.

4 Karvonen AM, Hyvarinen A, Roponen M, et al. Confirmed moisture damage at home, respiratory symptoms and atopy in early life: a birth-cohort study. Pediatrics 2009; 124: e329-e338.

5 Iossifova $\mathrm{YY}$, Reponen T, Ryan PH, et al. Mold exposure during infancy as a predictor of potential asthma development. Ann Allergy Asthma Immunol 2009; 102: 131-137.

6 Institute of Medicine. Damp Indoor Spaces and Health. Washington, The National Academies Press, 2004.

7 Gent JF, Ren P, Belanger K, et al. Levels of household mold associated with respiratory symptoms in the first year of life in a cohort at risk for asthma. Environ Health Perspect 2002; 110: A781-A786.

8 Stark PC, Celedon JC, Chew GL, et al. Fungal levels in the home and allergic rhinitis by 5 years of age. Environ Health Perspect 2005; 113: $1405-1409$.

9 Gehring U, Heinrich J, Hoek G, et al. Bacteria and mould components in house dust and children's allergic sensitisation. Eur Respir J 2007; 29: 1144-1153.

10 Douwes J. (1 $\rightarrow 3)-\beta$-D-glucans and respiratory health: a review of the scientific evidence. Indoor Air 2005; 15: 160-169.

11 Douwes J, van Strien R, Doekes G, et al. Does early indoor microbial exposure reduce the risk of asthma? The Prevention and Incidence of Asthma and Mite Allergy birth cohort study. J Allergy Clin Immunol 2006; 117: 1067-1073.

12 Haas D, Habib J, Galler H, et al. Assessment of indoor air in Austrian apartments with and without visible mold growth. Athmospheric Environment 2006; 41: 10.

13 Sahakian NM, Park JH, Cox-Ganser JM. Dampness and mold in the indoor environment: implications for asthma. Immunol Allergy Clin North Am 2008; 28: 485-505.

14 Schram-Bijkerk D, Doekes G, Douwes J, et al. Bacterial and fungal agents in house dust and wheeze in children: the PARSIFAL study. Clin Exp Allergy 2005; 35: 1272-1278.

15 Schaub B, Lauener R, von Mutius E. The many faces of the hygiene hypothesis. J Allergy Clin Immunol 2006; 117: 969-977.

16 Douwes J, Zuidhof A, Doekes G, et al. $(1 \rightarrow 3)-\beta$-D-glucan and endotoxin in house dust and peak flow variability in children. $A m$ J Respir Crit Care Med 2000; 162: 1348-1354.

17 Wong GW, von Mutius E, Douwes J, et al. Environmental determinants associated with the development of asthma in childhood. Int J Tuberc Lung Dis 2006; 10: 242-251.

18 Strachan DP. Hay fever, hygiene, and household size. BMJ 1989; 299: $1259-1260$.

19 Strachan DP, Harkins LS, Golding J. Sibship size and self-reported inhalant allergy among adult women. ALSPAC Study Team. Clin Exp Allergy 1997; 27: 151-155. 
20 Gehring U, Bischof W, Fahlbusch B, et al. House dust endotoxin and allergic sensitization in children. Am J Respir Crit Care Med 2002; 166: 939-944.

21 Gereda JE, Klinnert MD, Price MR, et al. Metropolitan home living conditions associated with indoor endotoxin levels. J Allergy Clin Immunol 2001; 107: 790-796.

22 Braun-Fahrlander C, Riedler J, Herz U, et al. Environmental exposure to endotoxin and its relation to asthma in school-age children. N Engl J Med 2002; 347: 869-877.

23 Chen CM, Gehring U, Wickman M, et al. Domestic cat allergen and allergic sensitisation in young children. Int J Hyg Environ Health 2008; 211: 337-344.

24 Heinrich J, Bolte G, Holscher B, et al. Allergens and endotoxin on mothers' mattresses and total immunoglobulin $\mathrm{E}$ in cord blood of neonates. Eur Respir J 2002; 20: 617-623.

25 von Berg A, Koletzko S, Grubl A, et al. The effect of hydrolyzed cow's milk formula for allergy prevention in the first year of life: the German Infant Nutritional Intervention Study, a randomized double-blind trial. J Allergy Clin Immunol 2003; 111: 533-540.

26 Douwes J, Versloot P, Hollander A, et al. Influence of various dust sampling and extraction methods on the measurement of airborne endotoxin. Appl Environ Microbiol 1995; 61: 1763-1769.

27 Douwes J, van der SB, Doekes G, et al. Fungal extracellular polysaccharides in house dust as a marker for exposure to fungi: relations with culturable fungi, reported home dampness, and respiratory symptoms. J Allergy ClinImmunol 1999; 103: 494-500.

28 Douwes J, Doekes G, Montijn R, et al. Measurement of $\beta(1 \rightarrow 3)$ glucans in occupational and home environments with an inhibition enzyme immunoassay. Appl Environ Microbiol 1996; 62: 3176-3182.

29 Radon K. The two sides of the "endotoxin coin". Occup Environ Med 2006; 63: 73-78.

30 von Mutius E, Braun-Fahrlander C, Schierl R, et al. Exposure to endotoxin or other bacterial components might protect against the development of atopy. Clin Exp Allergy 2000; 30: 1230-1234.
31 Braun-Fahrlander C. Environmental exposure to endotoxin and other microbial products and the decreased risk of childhood atopy: evaluating developments since April 2002. Curr Opin Allergy Clin Immunol 2003; 3: 325-329.

32 Sordillo JE, Hoffman EB, Celedon JC, et al. Multiple microbial exposures in the home may protect against asthma or allergy in childhood. Clin Exp Allergy 2010; 40: 902-910.

33 Caudri D, Wijga A, Scholtens S, et al. Early daycare is associated with an increase in airway symptoms in early childhood but is no protection against asthma or atopy at 8 years. Am J Respir Crit Care Med 2009; 180: 491-498.

34 Giovannangelo M, Nordling E, Gehring $\mathrm{U}$, et al. Variation of biocontaminant levels within and between homes: the AIRALLERG study. J Expo Sci Environ Epidemiol 2007; 17: 134-140.

35 Heinrich J, Holscher B, Douwes J, et al. Reproducibility of allergen, endotoxin and fungi measurements in the indoor environment. J Expo Anal Environ Epidemiol 2003; 13: 152-160.

36 Koopman LP, Smit HA, Heijnen ML, et al. Respiratory infections in infants: interaction of parental allergy, child care, and siblings: the PIAMA study. Pediatrics 2001; 108: 943-948.

37 Celedon JC, Litonjua AA, Ryan L, et al. Day care attendance, respiratory tract illnesses, wheezing, asthma, and total serum $\mathrm{IgE}$ level in early childhood. Arch Pediatr Adolesc Med 2002; 156: 241-245.

38 van Strien RT, Koopman LP, Kerkhof M, et al. Mite and pet allergen levels in homes of children born to allergic and nonallergic parents: the PIAMA study. Environ Health Perspect 2002; 110: A693-A698.

39 Bischof W, Koch A, Gehring U, et al. Predictors of high endotoxin concentrations in the settled dust of German homes. Indoor Air 2002; 12 : 2-9

40 Wijga A, Smit HA, Brunekreef B, et al. Are children at high familial risk of developing allergy born into a low risk environment? The PIAMA Birth Cohort Study. Prevention and Incidence of Asthma and Mite Allergy. Clin Exp Allergy 2001; 31: 576-581. 